\title{
The Individual and Society
}

This issue of the Journal contains a few items of historical interest. First, there is a review by Professor G.I. Abelev on alpha-fetoprotein. Professor Abelev's seminal work on this substance led to hypotheses on the oncofetal nature of tumor antigens, on re-trodifferentiation and dedifferentiation and eventually to the use of tumor markers in clinical practice. It is interesting to note that Professor Abelev has maintained his interest in this protein, its function and the control of its expression (fig. 1).

It seems that individuals engaged in the creative process - whether in the arts or sciences - are highly focused in their endeavors. Henry Moore, for example, spent his creative years sculpting the female form. (I am not sure he succeeded.) Degas painted ballet dancers, women coming out of the bath and horses. The creative genius seems to have endless ways of examining the same theme and is never satisfied.

Organizations, on the other hand, evolve and change as their goals and missions change. This is illustrated in Professor Hi-rai's contribution in this issue where he has given us a chronological listing of the affairs of our Society along with the dynamics that

Fig. 1. Professor Abelev, Moscow, delivered the opening plenary lecture at the X Vlth Congress of the International Society for Oncodevelopmental Biology and Medicine. The text of his presentation appears in the following pages.

62

Editorial

took place as the Society evolved. There were changes in the name of the Society, the Journal, and the publishers. Many of the individuals who were initially involved in the Society's activities continue to take an active interest in its affairs and share a common vision.

But why do societies change? Is it due to shifts in power, desire for consensus or reaction to outside events? Or is it simply in the nature of societies to evolve and become diffuse as it is for the individual to remain focused? In any case, the dynamics of growth and evolution require selection and adaptation.

How is this to be achieved? The architect says 'form follows function'. Organizations of various kinds have learned that they must delineate their goals and missions in order to measure progress. This is illustrated in the third piece of historical interest in this issue - the Society's new constitution and rules.

The constitution committee, chaired by Professor Neville, has provided us with a clear statement of the objectives of the Society and a structure around which the aims of the Society can be fulfilled. But there is still one major sticking point - and that has to do with the name of the Society. While the name Oncodevelopmenta $\Gamma$ has a clear connotation in English and expresses a broader concept than oncofetal, it does not translate well into other languages. (Besides, while the scope of the Society has evolved, its name is restricting and its mission, therefore, is not readily understood by outsiders.) 
Consequently, the constitution committee is looking for suggestions that will reflect the international character of the Society, its interest in basic and applied aspects of tumor biology and its roots in oncofetal research.

We look forward to hearing from you.

A. Malkin, Toronto 